\title{
Anti-diabetic activity of field cricket glycosaminoglycan by ameliorating oxidative stress
}

Mi Young Ahn ${ }^{1 *}$ D, Ban Ji Kim', Ha Jeong Kim¹, Jang Mi Jin², Hyung Joo Yoon ${ }^{1}$, Jae Sam Hwang ${ }^{1}$ and Byung Mu Lee ${ }^{3}$

\begin{abstract}
Background: Field cricket (Gryllus bimaculatus) is newly emerged as an edible insect in several countries. Antiinflammatory effect of glycosaminoglycan derived from this cricket on chronic disease animal model such as diabetic mouse has not been fully investigated yet. Thus, the objective of this study was to determine the antioxidative effect of such glycosaminoglycan on diabetic mouse.

Methods: To discover potential therapeutic agents, field cricket glycosaminoglycan (GbG) was tested in the present study. Its anti-oxidative activities in diabetic mice were determined based on its abilities to reduce glucose, ALT, AST, ALP, LDL-cholesterol and BUN levels. Dung beetle (C. molossus) glycosaminoglycan (CaG) was used as a positive control. Db mice were intraperitoneally administered for 1 month according to their group assignments: 1) normal (DB-Hetero); 2) control (DB-Homo); 3$) 5 \mathrm{mg} / \mathrm{kg}$ treatment of $\mathrm{CaG}$ (CaG5); 4) $5 \mathrm{mg} / \mathrm{kg}$ treatment of GbG (GbG5); and 5) $10 \mathrm{mg} / \mathrm{kg}$ treatment of metformin (Metformin 10).

Results: Blood glucose level decreased after 1st week of treatment with GbG. LDL-cholesterol and alkaline phosphatase levels were also inhibited by GbG. Markers of oxidative damage, such as protein carbonyl content and levels of hepatocellular biomarkers, were reduced in db mice treated with GbG. Especially anti-oxidative activities of catalase, superoxide dismutase and glutathione peroxidase were significantly increased in GbG treated group compared to those in the control (Db Homo). GbG was composed of heparin disaccharides. Its main N-glycan was identified as Hex ${ }_{9} \mathrm{GlCNAC}_{2}$ (m/z 1905.7) with neutral mono-sugar mainly comprising of hexose and $L(+)$ rhamnose by mass spectroscopy.
\end{abstract}

Conclusions: Sero-biochemical and hepatocellular anti-oxidant assay results in db mice suggest that cricket (G. bimaculatus) glycosaminoglycan might possess anti-oxidative effect in diabetic state.

Keywords: Cricket glycosaminoglycan, N-glycan, Homo db mice, Anti-oxidant enzyme

\footnotetext{
* Correspondence: amy@korea.kr

'Department of Agricultural Biology, National Institute of Agricultural

Sciences, RDA, 166 Nongsaengmyung-Ro, Iseo-Myun, Wanju-Gun 55365,

South Korea

Full list of author information is available at the end of the article
}

(c) The Author(s). 2020 Open Access This article is licensed under a Creative Commons Attribution 4.0 International License, which permits use, sharing, adaptation, distribution and reproduction in any medium or format, as long as you give appropriate credit to the original author(s) and the source, provide a link to the Creative Commons licence, and indicate if changes were made. The images or other third party material in this article are included in the article's Creative Commons licence, unless indicated otherwise in a credit line to the material. If material is not included in the article's Creative Commons licence and your intended use is not permitted by statutory regulation or exceeds the permitted use, you will need to obtain permission directly from the copyright holder. To view a copy of this licence, visit http://creativecommons.org/licenses/by/4.0/. The Creative Commons Public Domain Dedication waiver (http://creativecommons.org/publicdomain/zero/1.0/) applies to the data made available in this article, unless otherwise stated in a credit line to the data. 


\section{Background}

Eating insects is becoming common worldwide. Edible crickets acquired from industrial rearing systems as alternative food sources are increasingly used in several countries including the Netherlands. Gryllus bimaculatus (field cricket, Gb) water extract has been used in Oriental medicine as a crude antifebrile drug and a high blood pressure lowering agent. Recently, it has been shown that $\mathrm{Gb}$ water extract can lower blood ethanol metabolite concentrations by enhancing levels of liver mitochondrial alcohol and acetaldehyde dehydrogenases [1]. It also possesses anti-obesity effect by inhibiting adipose tissue accumulation in high-fat-diet induced diabetic rats [2]. We have recently shown that consumption of edible crickets has significant beneficial effects on gut microbiota in healthy adults [3].

Type-2 diabetes is known to be associated with oxidative stress. It influences vascular chronic diseases such as atherosclerosis, hypertension and nephropathy [4]. Antioxidant and anti-inflammatory activities of enzymatic hydrolysates and peptide fractions from selected heattreated edible insects including cricket have been ascertained [5] except for other carbohydrate components of field cricket. Indeed, all human cells are coated with an array of glycoproteins, glycolipids and polysaccharides named glycocalyx, the surface proteoglycan/glycoprotein layer [6]. Therefore, glycans can appeal distinct properties as biomarker targets [7]. Especially, N-glycans are ubiquitous in nature. They provide structural and functional stability to N-linked glycoprotein, with flexibility [8].

In the overview of a total insect component survey concept, as one of the functional components, Glycosaminoglycan (GAG), a mucin polysaccharide as one of functional components of edible insects, needs to be standardized and manufactured from a routine (no versatile) natural source with the same insect rearing conditions. The distinctive role of Gb GAG has been reported to possess anti-inflammatory effect in arthritis induced rat model [9]. It also has antiobesity [10] and antilipidemic [11] effects in high-fat-diet rats. Some GAGs have robust anti-oxidant activity that they can scavenge free radicals and repair cellular oxidative damages [12].

$\mathrm{Db} / \mathrm{db}$ mouse model is commonly used to conduct research on type 2 diabetes mellitus (DM) and its comorbidities including obesity and hypertension [13]. Some comparative studies have shown heparin sulfate to be a type of glycosaminoglycan plays a crucial role in proliferation, development and maturation of $\beta$ cells, thereby contributing to normal glucose hemostasis [14] and mouse $\beta$ cell survival in autoimmune type 1 diabetes mellitus [15]. However, the anti-inflammatory effect of glycosaminoglycan derived from this cricket on chronic disease animal model such as diabetic mouse has not been fully investigated yet. In the present study, the anti- oxidant activities of Gb GAG contributed to its antidiabetic activity. Attenuation of the complex metabolic depression in diabetes may be mediated via low levels of anti-oxidative enzyme, which repaired the cellular oxidative damage. Protein carbonyl level and induction of antioxidant enzyme ratios following GAG treatment of $\mathrm{db} / \mathrm{db}$ mice were also analyzed. Dung beetle (Catharsius molossus, Ca) GAG known to exhibit marked anti-ageing activity characterized by reduced oxidative damage in aged rats [16] was used as a positive control. In this work, we have also characterized purified N-glycans for deglycosylation of GbGAG followed by MS and MS/MS (MALDI TOF MS) analysis. In this study, we found that field cricket carried elements expressing glycosaminoglycan with anti-oxidant activities to ameliorate cellular oxidative damage in diabetes.

\section{Methods}

\section{Preparation of field cricket glycosaminoglycan}

Field crickets (G. bimaculatus) were obtained from a cricket farm located in Hwasung, Korea. They were freeze-dried in NAAS (National Academy of Agricultural Science), South Korea. Dried dung beetles (C. molossus) were purchased from a local market in China. They were prepared by Chinese phamacognosists and posted to NAAS in 2002 (no law regulation time). These insects were defatted, freezing dried, and stored in a deep freezer.

Each insect glycosaminoglycan was purified with a method as reported previously [17], involving removal of fat with ethanol and acetone, protein enzymatic hydrolysis by treatment with alcalase (Sigma Aldrich, USA), protein precipitation with trichloroacetic acid (5\%), impure materials cleansing with detergent such as cetylpyridinium chloride (5\%), and dissolving of non-glycosaminoglycan with $2.5 \mathrm{M} \mathrm{NaCl}$. GAGs were then acquired through cold ethanol precipitation, centrifugation, and DEAE Sephadex A-25 gel chromatography. For structural identification of these GAGs, main peaks of digested Gb GAG after coincubation with heparinase I, II, or III were pooled using SAX column (Phenomenex, USA) with high performance liquid chromatography (HPLC) to determine its purity. They were compared with heparin disaccharides or carbohydrate standards with an ESI Mass Spectrometer (SYNA PT G2, Waters, U.K.).

$\mathrm{N}$-glycan preparation derived from cricket glycosaminoglycan A purified cricket glycosaminoglycan through DEAE Sephadex A-25 gel from $0.5 \mathrm{M} \mathrm{NaCl}$ fraction (GbG 0.5 M) was further purified to obtain a low molecular weight. Using a previously reported method [18], this GbG was denatured by boiling for $10 \mathrm{~min}$. It was then incubated with $1000 \mathrm{U}$ of peptide $\mathrm{N}$-glycosidase $\mathrm{F}$, PNGase $\mathrm{F}$ (New England biolabs, USA) to release Nglycan. This cricket N-glycan was then solid-phase 
extracted using Graphitized carbon cartridges (extract clean $^{\text {TM }}$ carbo, Grace davision discovery Sciences, USA). $\mathrm{N}$-glycan derived from GbG was then characterized by liquid chromatography for mass and mass/mass analyses with a MADI-TOF analyzer (AXIMA Resonance, Shimadzu).

\section{Neutral mono-sugar composition of digested N-glycan on the basis of GC-MS analysis}

Isolated $\mathrm{Gb} \mathrm{N}$-glycan $(100 \mu \mathrm{L})$ was $\mathrm{HCl}$-hydrolyzed, trimethylsilylated using $\mathrm{N}, \mathrm{O}$-Bis(trimethylsilyl)trifluoroacetamide containing $1 \%$ trimethylchlorosilane (Sigma Co., USA) and then injected into a GC-MS (Agilent, USA) [11].

\section{Animals}

Two kinds of $\mathrm{db}$ mice, BKS.Cg- $\mathrm{m}+/+$ Lepr $^{\mathrm{db}}$, heterozygous $(\mathrm{db} /+)$ (DB-Hetero, normal) and homozygotes ( $\mathrm{db} / \mathrm{db})$ (DB-Homo, diabetes) male db mice at 12 weeks of age, were purchased from Samtako Co. Ltd. (Osan, Korea). All experiments were performed in accordance with $\mathrm{NIH}$ Guidelines for Care and Use of laboratory Animals. Experimental protocols were approved by Laboratory Animals' Ethical committee of National Institute of Agricultural Sciences, Republic of Korea (approval number: NIAS201605).

These mice were allocated into two control groups (negative and positive controls) and two GAG treatment groups (11 mice per group). They were distributed according to their similarity in weight $(27.86 \pm 1.14 \mathrm{~g}$ for DB-Hetero, $46.73 \pm 4.73 \mathrm{~g}$ for DB-Homo). Treatments were intraperitoneally offered in phosphate buffered saline daily under normal diet (AIN-76A rodent diet, Research Diet). The following treatment groups were used: 1) normal (DB-Hetero); 2) control (DB-Homo); 3) $5 \mathrm{mg} / \mathrm{kg}$ treatment of CaG (CaG5); 4) $5 \mathrm{mg} / \mathrm{kg}$ treatment of GbG (GbG5); and 5) $10 \mathrm{mg} / \mathrm{kg}$ treatment of metformin (Metformin 10) as positive control. After overnight fast, euthanasia was performed under light $\mathrm{CO}_{2}$ inhalation at the end of one-month treatment. Blood samples were collected from abdominal aorta with a syringe. Organs of mice were extracted via autopsy.

\section{Body weight and estimation of blood glucose levels}

Body weights were weekly determined. Non-fasting glucose levels in blood samples drawn from tail veins were determined weekly using a blood glucose Nocodingone detector (Theragenetex.Co., Sungnam, Korea). On the last day of the one-month treatment schedule in a fasted state, serum glucose levels were determined with an auto-analyzer and compared with those of mice treated with metformin, a positive control drug for type 2 diabetes [19].

\section{Organ and adipose fat weights}

Absolute weights of adrenal glands, kidneys, heart, liver, lung, spleen, stomach, and pancreas were measured. Their relative weights (organ-to-body ratio) were then calculated. Abdominal (including omental and perirenal) and epididymal fat to-body weight ratios of each group were also determined and compared with those of the DB-Homo control group.

\section{Blood sampling and sero-parameter assay}

After treatment with $\mathrm{CaG5}$, GbG5, or metformin10 for 1 month, all non-diabetic control, db control, and db treated mice were blood sampled and evaluated for the following parameters with an auto analyzer (Hitachi 7060 Automatic Clinical Analyzer, Tokyo, Japan) according to Green Cross Lab's manual: albumin, hyaluronic acid, free fatty acid, ALP, AST, ALT, lactic dehydrogenase, creatinine phosphokinase, total cholesterol, triglyceride, HDL cholesterol, LDL cholesterol, creatinine, BUN, total protein, $\mathrm{Na}, \mathrm{Cl}$, creactive protein, $\mathrm{Ca}, \mathrm{K}$, total IgE, $\mathrm{C}$-peptide, and insulin.

\section{Carbonyl content detection for oxidative protein damage}

Protein oxidative stress was evaluated by measuring protein carbonyl contents in the supernatant of liver homogenate and blood after centrifugation using an OxiSelect ${ }^{\mathrm{si}}$ protein carbonyl ELISA kit (Cell Biolabs, Inc., San Diego, CA, USA).

\section{Measurements of oxidative enzyme activities}

Supernatant of each liver homogenate after centrifugation was obtained to determine catalase, glutathione peroxidase, glutathione s-transferase, and superoxidase dismutase activities using an OxiSelect ${ }^{\mathrm{tm}}$ ELISA kit as described previously [12, 20, 21].

\section{Endothelial nitric oxide synthase, laminin and VEGF on diabetic endothelial cells}

Endothelial vasorelaxation related to $e \mathrm{NOS}$ and growth factor were also measured in diabetic type 2 microvascular endothelial cells (D- HMVECs) (Clonetics ${ }^{\mathrm{Tm}}$, diabetic type II, Lonza CC-2928, Cambrex, Walkersville, USA). D-HMVECs were pretreated with $0.2 \mathrm{mg} / \mathrm{ml}$ of either GAG or Pravastatin and incubated prior to determination of $e$ NOS [22] and VEGF [23] (Quantikine, R\&D Systems, Inc., Minneapolis, USA). Laminin level in diabetic HMVEC cells was measured using a Quantimatrix ${ }^{\mathrm{Tm}}$ human laminin ELISA kit (Millipore, Billerica, USA). Positive controls were Pravastatin (CJ Healthcare Co., Seoul, Korea) and chitosan (Sigma Co., USA).

\section{Adipocyte density and pathological observation}

Excised organs including kidneys, heart, liver, lung, spleen, stomach, pancreas, testis, and adipose tissues of $\mathrm{db}$ mice were fixed with $10 \%$ neutral formalin. After paraffin molding, their slides were stained with hematoxylin and eosin and toluidine blue $\mathrm{O}$, examined with a light microscope (Leica CTR6000, Hesse, Germany), and photographed. Toluidine blue $\mathrm{O}$ stained adipocyte densities (cells $/ \mathrm{mm}^{2}$ ) 
in treated and control tissues were determined by counting (original magnification, $\times 400$ ).

\section{Statistical analysis}

Analysis of variance (ANOVA) was performed to determine differences in means and standard errors of parameters of different groups. To determine significant differences between control and treated groups, Student's $t$-test was performed. Same groups were subjected to repeated measures ANOVA at different time points followed by pairwise multiple comparisons (Tukey's test).

\section{Results}

\section{Field cricket glycosaminoglycan preparation}

From $1 \mathrm{~kg}$ of each dried insect, the yield of freeze-dried GAG powder was about $1.52 \mathrm{~g}$ for $\mathrm{CaG}$ and $3.4 \mathrm{~g}$ for $\mathrm{GbG}$.

\section{Analysis of field cricket glycosaminoglycan}

$\mathrm{N}$-glycan was refined from cricket (G. bimaculatus) origin insect glycosaminoglycan. The concentration of sodium chloride used in the ion exchange chromatography process for elution was $0 \mathrm{M}$ (Fig. 1a). By confirming whether it was the low molecular weight or the degree of purity to confirm performed SAX (strong anion exchange process, Phenomex, $250 \times 10 \mathrm{~mm}$ ) - HPLC and $232 \mathrm{~nm}$ after glycan lyase (the heparinase I,II,III and the chondroitin ABCase) processing amid the single Peak was detected or purity was confirmed in Fig. 1a. SAX-HPLC result showed that the final low molecular weight chromatogram of cricket glycosaminoglycan noted from the major SAXHPLC peak glycosaminoglycan of insect existed as one. After pooling this single peak followed by heparinase II treatment, heparin disaccharide IV-H and I-S standard fragments were detected in this peak using MADI-TOF mass data analysis program.

\section{Identification of $\mathrm{N}$-glycan derived from $\mathrm{GbG}$}

We have already noted the monosaccharide composition of GbG [11]. N-glycans of $\mathrm{CbG}$ were identified as $\mathrm{Hex}_{6}$, $\mathrm{Hex}_{5} \mathrm{GlcNAc}_{2}, \mathrm{Hex}_{6} \mathrm{GlcNAc}_{2}, \mathrm{Hex}_{7} \sim 10 \mathrm{GlcNAc}_{2}$ and $\mathrm{m} / \mathrm{z}$

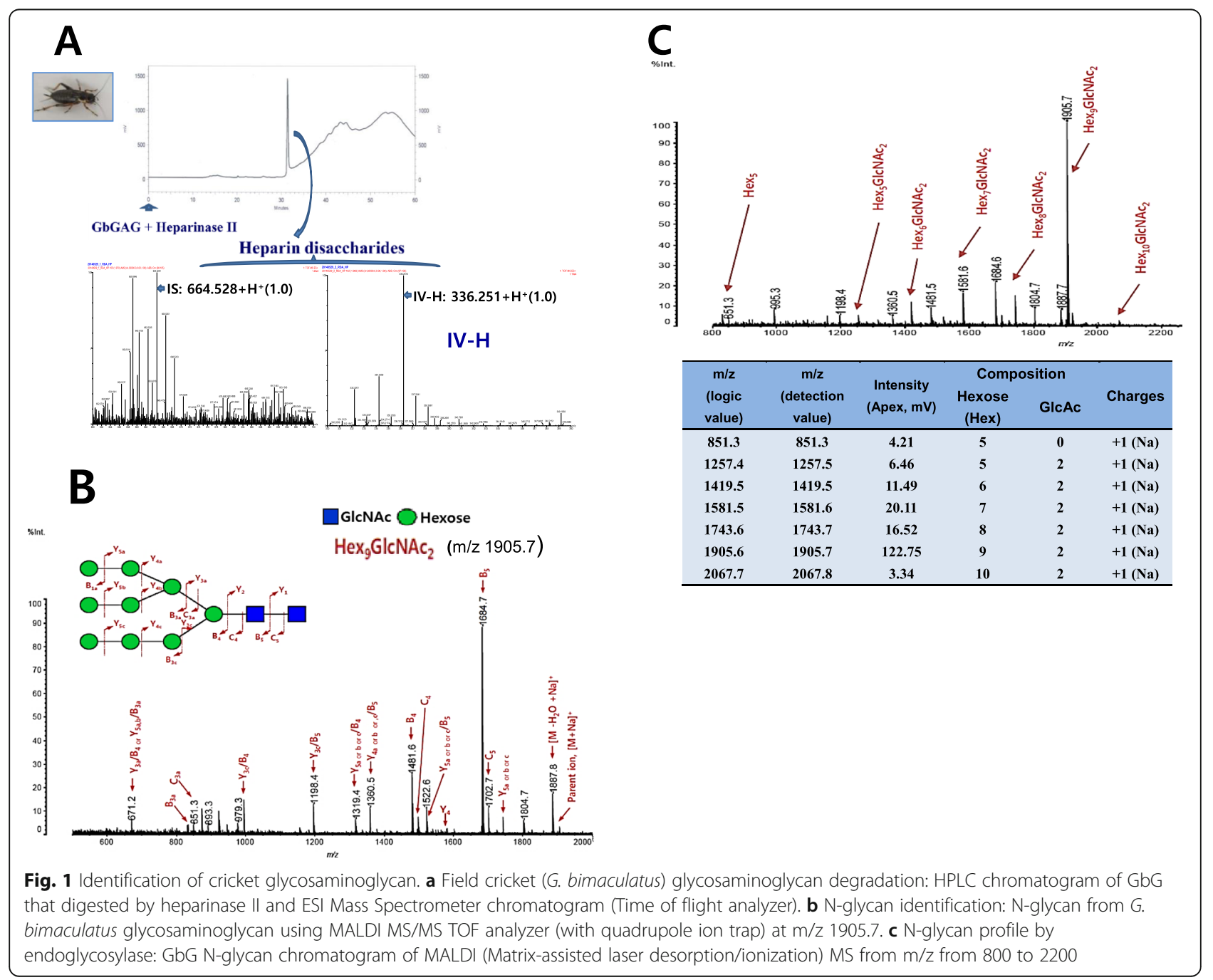


1905.7 of $\mathrm{Hex}_{9} \mathrm{GlcNAc}_{2}$ by mass/mass spectroscopy (Fig. 1b and c). We found that the neutral mono-sugar of $\mathrm{N}$-glycan derived from $\mathrm{GbG}$ was mainly hexose $[\mathrm{L}(+)$ rhamnose $81.10 \%, \mathrm{D}(-)$ ribose $7.16 \%, \mathrm{D}(+)$ arabinose $5.91 \%, \mathrm{D}(-)$ fructose $1.91 \%$ and $\mathrm{D}(+)$ glucose $1.62 \%$ ] by using TMS Gas chromatography-Mass data base.

\section{In vivo $\mathrm{db}$ mouse study}

\section{Body weight and abdominal fat detection}

There were significant differences (DB-Hetero vs. DBHomo, $p<0.01$ ) in mean body weight between the normal (DB-Hetero) and all diabetic mice of treatment groups (Fig. 2) including DB-Homo during one-month of treatment (Fig. 3a). However, there were no significantly differences in total mean body weight between diabetic control (DB-Homo) and treatment groups at 1 week after beginning treatment. Mean body weights at the end of 4 weeks of treatment were as follows: DB-Hetero, $30.6 \mathrm{~g}$; DBHomo, 53.5 g; CaG5, 48.6 g (CaG5 vs. CON, $p<0.05$ ); GbG5, 48.4 g; and Metformin10, $47.7 \mathrm{~g}$ (Metformin10 vs. CON, $p<0.05$ ) (Fig. 3a). Abdominal fat weight of the treated GAG group over 1 month showed significant difference from that of the DB-Hetero (normal db mice) group, but not from that of the DB-Homo group (Fig. 3a).

\section{Effects of GbG5 on blood glucose level}

Glucose levels in homozygotes $\mathrm{db}$ mice were found to be increased with aging (from $486.5 \mathrm{mg} / \mathrm{dL}$ at the age of 12 weeks to $578.2 \mathrm{mg} / \mathrm{dL}$ at the age of 17 weeks).

Early GbG treatment in the first week lowered blood glucose level in db mice (Fig. 3b), whereas non-fasting blood glucose level in the fourth week of GbG treatment remained unchanged and no lower than at other weeks. Blood glucose levels analyzed during the first week compared with levels in the fourth week in different treatment groups via Tukey's test, showed a statistically significant difference $(p=0.039)$.
As a positive control, low-dose metformin was used, which did not effectively reduce the non-fasting blood glucose levels compared with other GAG. Meanwhile, the fasting serum glucose levels on the last day of 1month treatment were slightly decreased in the autoanalyzer analysis (Fig. 3b). Each treatment group compared with DB-Hetero showed a statistically significant difference $(P<0.23)$ in Tukey's test.

\section{Sero-biochemical effects after treatment with GbG}

Serum albumin, alkaline phosphatase (ALP), ALT (GPT) and AST (GOT) levels in CaG- and GbG- treated groups were lower than those in the control group at 1 month after treatment, although these decreases were not statistically significant (Fig. 3c). BUN mean levels (mg/dL) in GbG-treatment $\mathrm{db}$ mice were lower than those in the control group. Creatinine mean levels $(\mathrm{mg} / \mathrm{dL})$ were also slightly decreased by GbG treatment (Fig. 3d). HDL-, LDL-cholesterol (Fig. 3d), and other sero-parameters (hyaluronic acid, calcium, creatinine kinase, free fatty acid, c-reactive protein, total protein, C-peptide and insulin (data not shown) detected in GbG treated group did not show any significant difference compared to those of $\mathrm{CON}$.

\section{Reduction of oxidative damages}

Protein carbonyl concentrations in blood samples were significantly decreased after treatment with insect glycosaminoglycans. Decreased mean carbonyl content levels (nmol/mg protein) were: DB-Homo, 7.25; CaG5, 5.91 (CaG5 vs. CON, $p<0.05$ ); GbG5, 5.91 (GbG5 vs. CON, $p<0.05$ ); and Metformin10, 6.74 (Fig. 4a). However, there were no statically significant differences in hepatocyte carbonyl contents between control and treatment groups of db mice (Fig. $4 \mathrm{a}$ ).

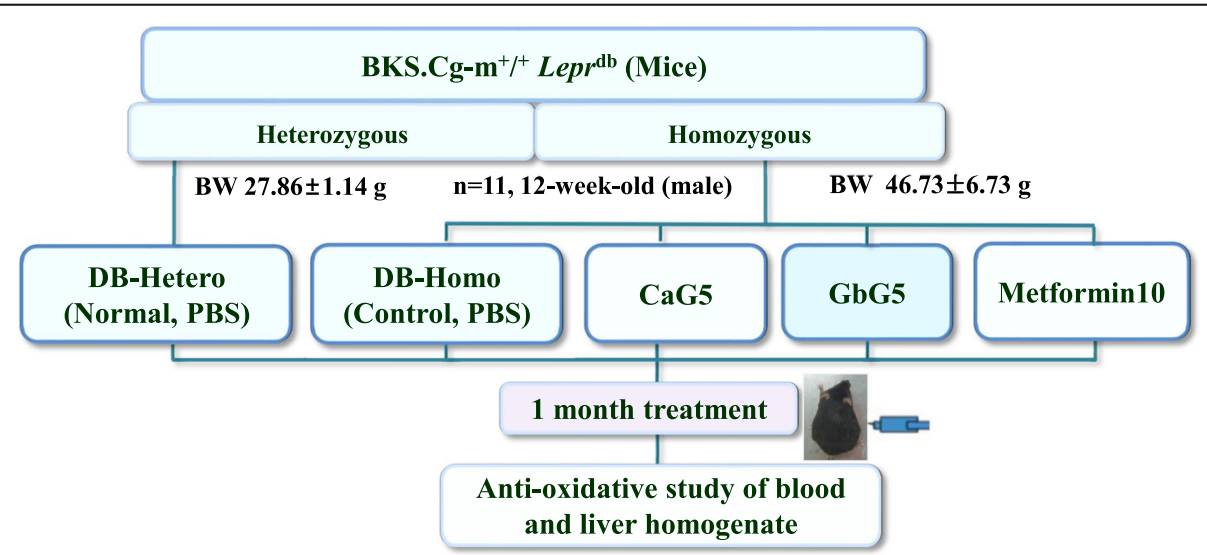

Fig. 2 Animal experimental design: Scheme of Db mice treated with CaG or GbG over 1 month. CaG5: dung beetle (C. molossus) glycosaminoglycan $5 \mathrm{mg} / \mathrm{kg}$; GbG5: field cricket (G. bimaculatus) glycosaminoglycan $5 \mathrm{mg} / \mathrm{kg}$, and Metformin10: Metformin $10 \mathrm{mg} / \mathrm{kg}$ 
A
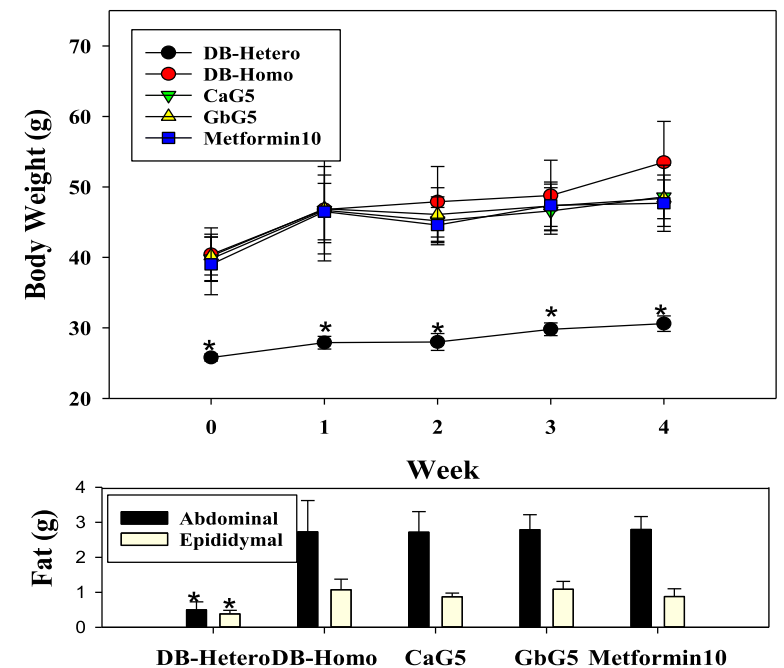

C

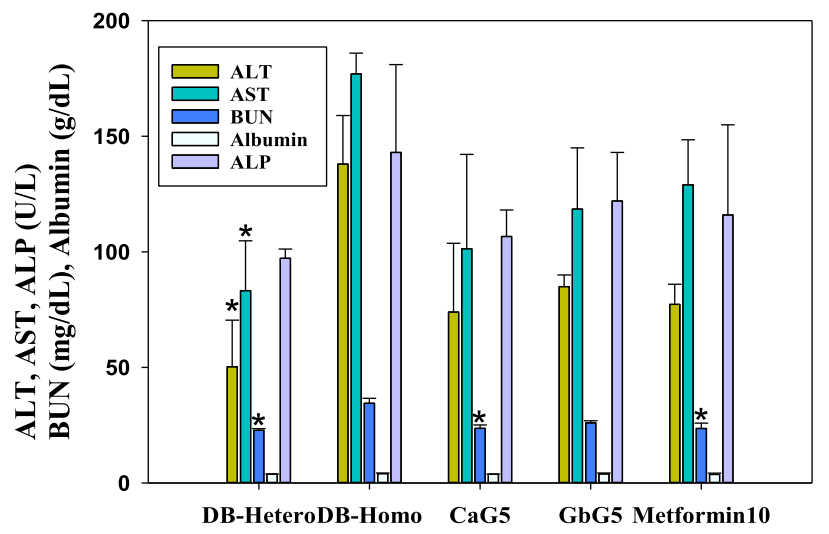

B

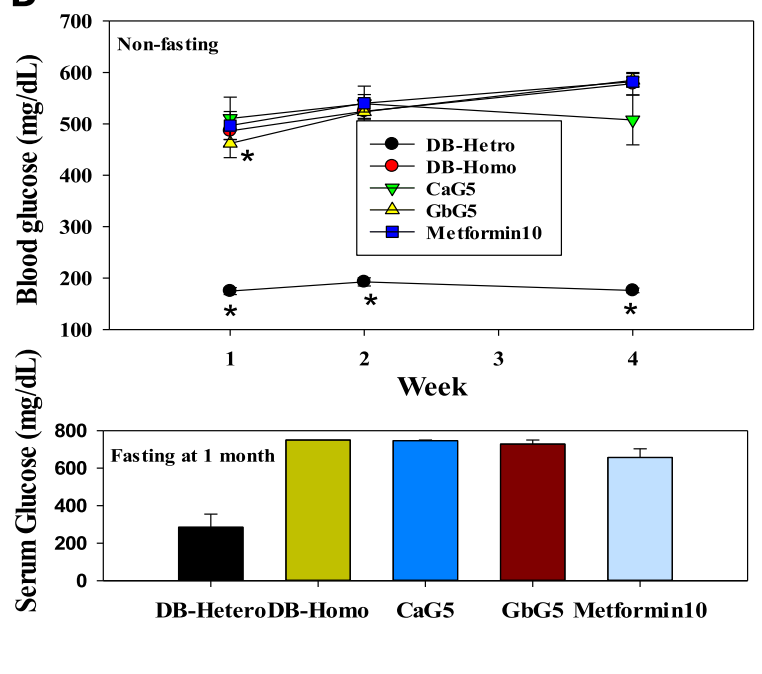

D
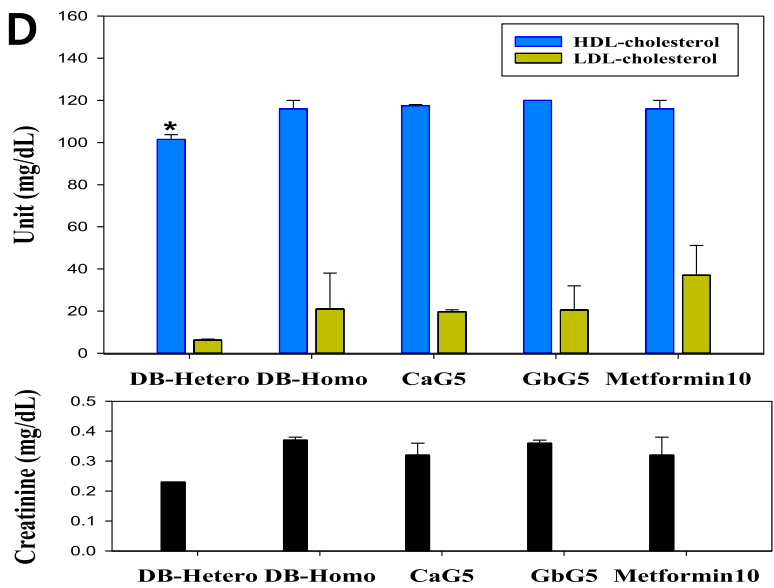

Fig. 3 Effect of a Body weight, abdominal fat and epididymal fat, b blood glucose level, c Serological level of ALT, AST, ALP, BUN and albumin level, $\mathbf{d}$ HDL-cholesterol, LDL-cholesterol and creatinine levels in db mice treated with G. bimaculatus glycosaminoglycan for a 1 month. ${ }^{*} p<0.05$, compared with CON (DB-Homo, diabetic) group

\section{Increase of oxidative enzyme activities}

As shown in Fig. 4b, levels of catalase, GPx and GST were increased in $\mathrm{db}$ mice treated with GbG for a month. Mean catalase activities (mg protein/min) in db mice liver after 1 month of GAG treatment were significantly increased in treatment groups: CaG5 (CaG5/CON: 110.6\%, CaG5 vs. CON, $p<0.05$ ); GbG5 (GbG5/CON: 114.9\%, GbG5 vs. CON, $p<0.05$ ); and Metformin10 (Met/CON: 102.2\%). Catalase activities in GAG-treated liver groups were all increased compared to those in the control group. Mean glutathione peroxidase activities (Unit/mg protein) in all GAG treated groups were also increased in $\mathrm{db}$ mice: CaG5 (CaG5/CON: 235.7\%); GbG5 (GbG5/CON: 248.0\%, GbG5 vs. CON, $p<0.05)$ and Metformin10 (Met/CON: 135.1\%). Mean activity $(\mathrm{nmol} / \mathrm{min} / \mathrm{ml})$ ratios of glutathione-stransferase as a detoxifying hepatic enzyme, were ensued compared with control as follows: CaG5 (109.3\%); GbG5, (117.5\%); and Metformin10 (97.6\%). Mean activities (nmol/ $\mathrm{min} / \mathrm{ml}$ ) of superoxide dismutase as a strong free radical scavenger were significantly increased in treatment groups: CaG5 (126.1\%, CaG5 vs. CON, $p<0.05)$ and GbG5 $(125.7 \%$, GbG5 vs. CON, $p<0.05)$ (Fig. 4c).

\section{Adipocyte density and pathological observations}

Pancreas tissues were attenuated gradually diabetic damaged lesion after treatment with these GAG or metformin compared to those of non-treated Homo-db mice based on hematoxylin and eosin staining results. In general, the adipocyte cell density was counted using toluidine blue stained deposits (Fig. 5a).

Adipocyte density (cells $/ \mathrm{mm}^{2}$ ) was decreased in treated pulmonary, liver and kidney tissues compared to that in the control group based on toluidine blue $\mathrm{O}$ staining. However, in other organ, pancreatic tissues, toluidine stain deposit number was not significantly decreased in treated group as shown in Fig. 5b. Histologically, the diabetic control group 


\section{A}

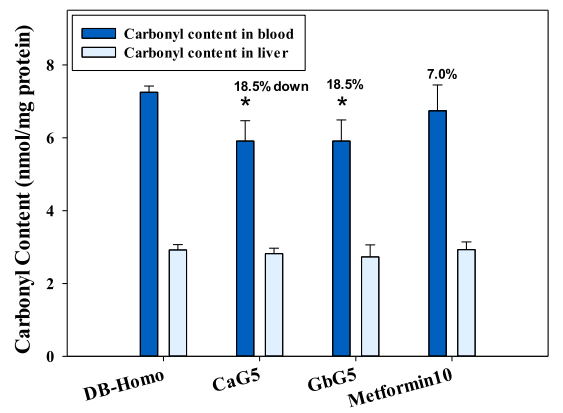

C

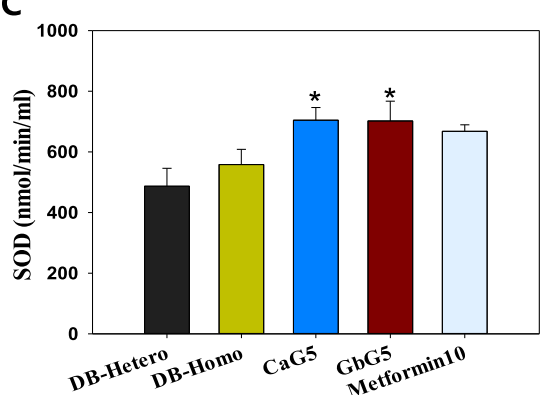

B

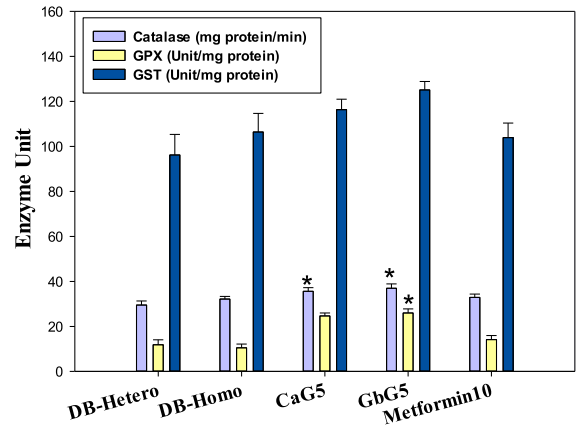

Fig. 4 a Anti-oxidative effect of $\mathrm{CaG}$ or GbG on (a) carbonyl content, b catalase content, glutathione peroxidase (GPX), or glutathione-s transferase (GST) and c superoxide (SOD) content. Each value represents mean \pm S.D. statistically significant from DB-Homo group $\left.{ }^{*} p<0.05\right)$

(DB-Homo) showed evidence of severe damage characterized by transformation of borders, vacuolization and cytoplasmic degranulation compared to the normal control group (DB-Hetero) of pancreatic islet (Fig. 5a). Damaged pancreas tissues with diabetic damaged lesions were reduced gradually after these GAG or metformin treatment based on the hematoxylin and eosin staining results. Administration of CaG5 or GbG5 ameliorated these damaged pancreatic islets up to $25 \%$. According to liver tissue photograms from CON, DB-Homo, CaG5, GbG5 and metformin10 samples, the morphology of liver tissues treated with
GbG5 showed the liver to be in an ameliorated diabetic, damaged state (Fig. 5c).

\section{In vitro D-HMVEC cell study}

The role of endothelial nitric oxide synthase, laminin and VEGF on HUVEC

Endogenous nitric oxide ( $e \mathrm{NOS}, \mathrm{pg} / \mathrm{ml}$ ) levels in human cardiac microvascular endothelia cells (from diabetic type 2) were decreased after treatment with 5 or $10 \mathrm{mg} /$ ml of GbG5 (67.4\%) or GbG10 (62.9\%). However, after treatment with $10 \mathrm{mg} / \mathrm{ml}$ pravastatin, $e$ NOS $(\mathrm{pg} / \mathrm{ml})$ was

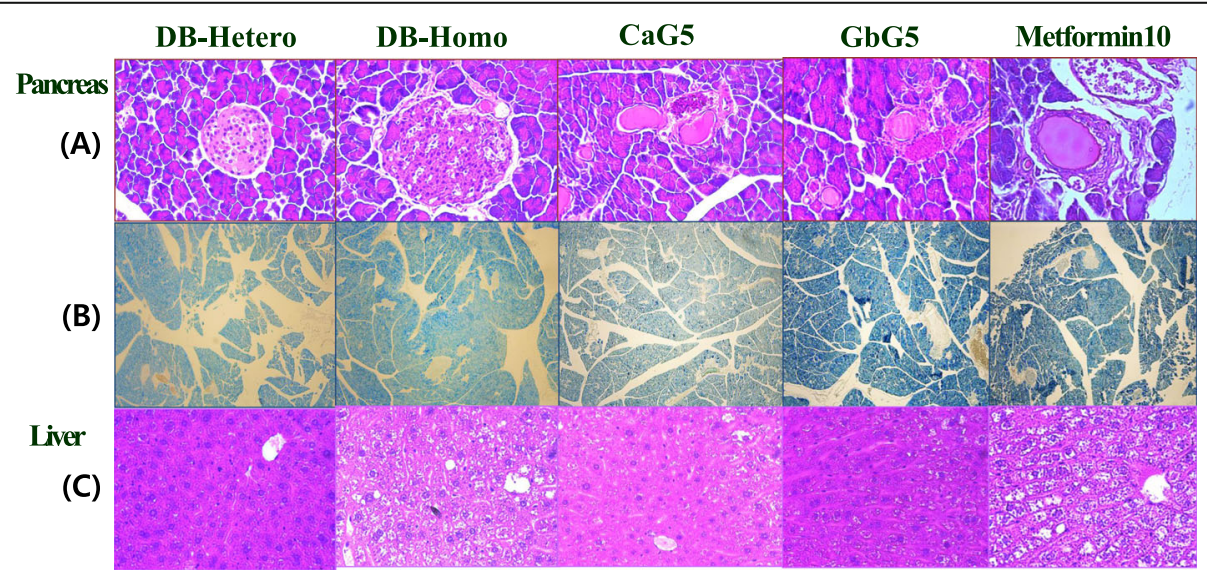

Fig. 5 Microscopy observation of pancreas $(\times 400)$, a hematoxylin \& eosin stained cells, $\mathbf{b}$ toluidine O-Blue stained deposits: adipocyte and $\mathbf{c}$ liver $(\times 50)$, hematoxylin \& eosin stained cells in db mice treated with some GAG, $(n=3$ per group) 
significantly increased: Pravastatin10 (160.16\%, Pravastatin10 vs. CON, $p<0.05$ ) (Fig. 6a). Laminin level (ng/ $\mathrm{ml}$ ) in the same cell type was not significantly changed after treatment with either GbG or positive control: GbG5 (102.9\%); GbG10 (97.6\%); Pravastatin (132.7\%) and chitosan (196.9\%). VEGF levels $(\mathrm{pg} / \mathrm{ml})$ in HMVEC diabetic cells showed dose-dependent increases after GbG treatment: GbG5 (114.7\%); GbG10 (175.1\%, GbG10 vs. CON, $p<0.05)$; Pravastatin10 (112.7\%) and chitosan10 (185.8\%) (Fig. 6b).

\section{Discussion}

Glycosaminoglycan treatment effectively decreased blood glucose levels in diseases associated with hyperglycemia [24]. Glycosaminoglycan, extracted from the mucous membrane of crickets' inner cortex, has been reported to exhibit anti-lipidemic effect on rats with high-fat dietinduced diabetes [11]. It also lowered the blood pressure [25] and induced anti-inflammatory effects in rats with adjuvant-induced edema [9]. Results of our db mouse study show that after treatment with each glycosaminoglycan, the serum BUN levels decreased (CaG5, 68.5\%; GbG5, 75.5\% and Metformin10, 68.4\%) compared with the levels in the DB-Homo group. Furthermore, the total levels of albumin, alkaline phosphatase, ALT, AST and creatinine were also decreased by GAGs, which ameliorated metabolic activation of hepatocytes. The oxidative enzymes expressed serum biochemical biomarkers including albumin, ALP, ALT, AST and creatinine. Serum insulin level was not significantly altered between control and treated groups. The $\mathrm{db}$ mouse model of type II diabetes is not primarily dependent on blood glucose control hormone and insulin secretion but is affected by $\beta$-cell dysfunction and insulin resistance. Hence, when we analysed the serum $\mathrm{C}$-peptide and insulin levels between the insect GAG-treated groups and the $\mathrm{db}$ untreated $(\mathrm{CON})$ group, no difference was seen in the levels of C-peptide $(<0.1 \mathrm{ng} /$
$\mathrm{mL})$ and insulin $(<0.2 \mu \mathrm{U} / \mathrm{mL})$ between groups according to Green-Cross Lab Cell analysis. Oral glucose tolerance tests in diabetic mice using these insect GAGs are necessary to ascertain their anti-diabetic effects even though they were not accurate because the orally administered GAGs are also digested and increase the levels of mono (neutral, amino and acid) sugars.

In fact, specific functional groups including epoxy, hydroxyl and carbonyl contribute to potent free radicalscavenging activity [26]. In addition to anti-oxidant activities, GbG exhibits unremarkable anti-diabetic activity without adverse effects in in vitro or in vivo models.

Glycosaminoglycan also acts as an anti-oxidant by scavenging free radicals that induce cellular oxidative damage [27]. However, the effect of enzymes such as SOD, along with cofactors $\mathrm{Cu}$ or $\mathrm{Zn}$, on cardiovascular target sites results in increased anti-oxidant defence [28]. Levels of antioxidative enzymes and activities of catalase, glutathione peroxidase, glutathione-s-transferase and SOD were also increased by GbG. Thus, hepatocellular oxidative stress triggered by free radical damage is attenuated by these anti-oxidant enzymes. In our db mice experiment, GbG5 appeared to act as an antioxidant. It increased catalase activity by $114.9 \%$, GPX by $248.1 \%$, GST by $117.6 \%$ and SOD by $125.7 \%$. In terms of the blood cellular oxidative damage, protein oxidative damage was also reduced (CaG5 by $18.5 \%$; GbG5 by $18.5 \%$ and Metformin 10 by $7.0 \%$ ) by these GAGs based on blood neutrophil carbonyl content.

However, as shown in Fig. 3d, increased HDL cholesterol protects blood vessels and LDL cholesterol reduction is a positive outcome. However, from the perspective of a human clinical study, we recognise that a GAG-lyase deficient patient is an exception in that the GAGs and mucopolysaccharides may persist in the blood.

Purified human GAGs have been shown to reduce cell death, limit DNA fragmentation and thus protein oxidation,
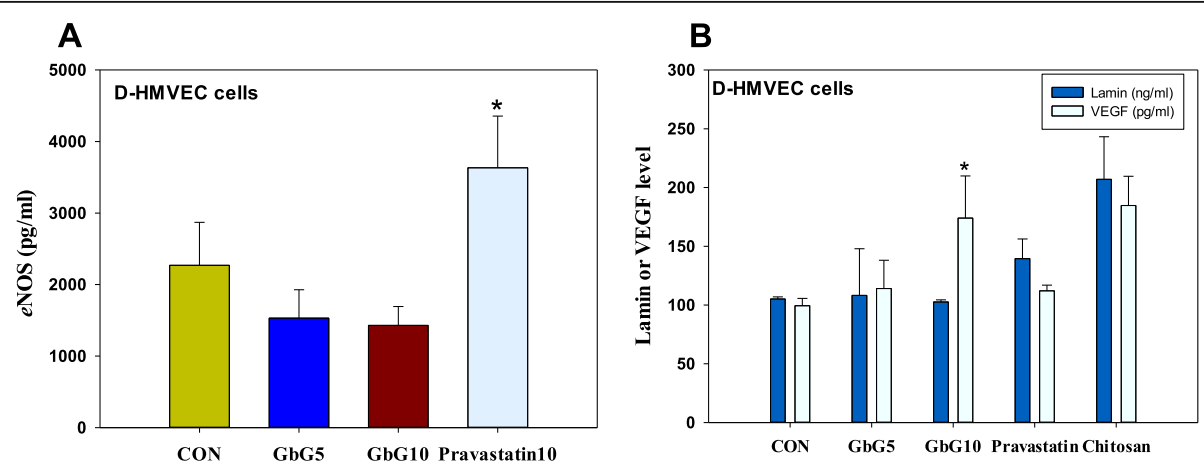

Fig. 6 Effect of a endothelial nitric oxide synthase (eNOS), b laminin and vascular endothelial growth factor (VEGF) on human microvascular endothelial cells from type 2 diabetics. As a D- HMVEC cell study, GbG5: G. bimaculatus glycosaminoglycan 5 mg/ml; GbG10: G. bimaculatus glycosaminoglycan $10 \mathrm{mg} / \mathrm{ml}$; Pravastatin: pravastatin $10 \mathrm{mg} / \mathrm{ml}$ and Chitosan: chitosan $10 \mathrm{mg} / \mathrm{ml}$. Each value represents mean \pm S.D. statistically significant from DB-Homo $\left.{ }^{*} p<0.05\right)$ 


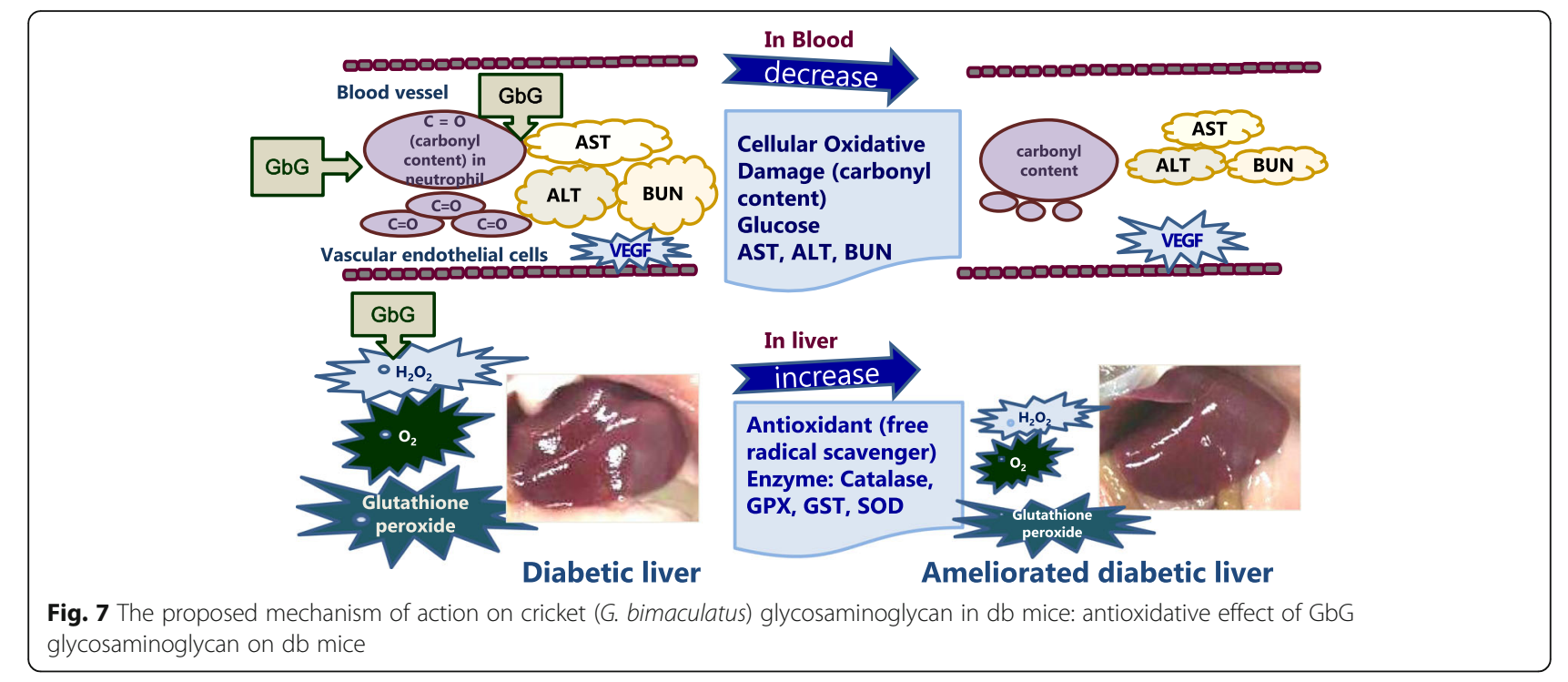

decrease the level of $\mathrm{OH}$. generation and lactate dehydrogenase activity, inhibit lipid peroxidation and thereby improve endogenous antioxidant defences [29]. However, mucopolysaccharidosis type II (MPS II), a lysosomal storage disorder caused by deficient enzyme iduronate-2-sulphatase that is responsible for the degradation of glycosaminoglycans dermatan and heparin sulphate, is protected against lipid peroxidation while protein damage in these patients is repaired by enzyme replacement therapy [30]. The proposed mechanism of action of cricket glycosaminoglycan in $\mathrm{db}$ mice is summarised in Fig. 7. The postulated anti-oxidative action of cricket glycosaminoglycan in type 2 diabetic mice is supported by findings suggesting that GAG such as the low-molecular-weight heparin, increases SOD levels and inhibits oxidative stress [31] and that glycosaminoglycan derived from Urechis unicinctus significantly enhances liver SOD and GSH-Px activities [24]. Further clinical studies are needed to verify the proposed mechanism. Heparinoid (a type of glycosaminoglycan) sources from animals and fish may be associated with viral infection in addition to endangering marine life such as whales and sharks. Therefore, an in vitro insect rearing system provides a large quantity with the same quality control.

\section{Conclusions}

The results based on serum biochemical and hepatocellular antioxidant assays in db mice suggest that cricket ( $G$. bimaculatus) glycosaminoglycan can be used as a natural antioxidant agent and functional food for the treatment of diabetes.

\section{Abbreviations}

ALP: Alkaline phosphatase; ALT (GPT): Glutamate pyruvate transaminase; AST (GOT): Glutamate oxaloacetate transaminase; BUN: Blood urea nitrogen; CaG: Dung beetle (C. molossus) glycosaminoglycan; CaG5: C. molossus glycosaminoglycan 5 mg/kg; CON: Control group; GAG: Glycosaminoglycan;
DB(db): Diabetic; DB-Hetero: Heterozygotes db normal mice; DBHomo: Homozygotes diabetic mice; D-HMVEC: Diabetic type2 microvascular endothelial cell; GbG: G. bimaculatus (a type of cricket) glycosaminoglycan; GbG5: G. bimaculatus glycosaminoglycan 5 mg/kg; GC-MS: Gas

chromatography with mass detector; GPx: Glutathione peroxidase; GST: Glutathione s-transferase; HDL: High-density lipoprotein; LDL: Lowdensity lipoprotein; Metformin10: Metformin $10 \mathrm{mg} / \mathrm{kg}$; eNOS: Endothelial nitric oxide synthase; SOD: Superoxide dismutase; VEGF: Vascular endothelial growth factor; TMS: Trimethylchlorosilane

\section{Acknowledgements}

The authors acknowledge National Institute of Agricultural Sciences for financial (RDA, PJ011853), technical supports and also Div. mass spectrometry research of Korean basic science institute for analysis of $\mathrm{N}$-glycan sequence data.

\section{Authors' contributions}

MYA performed most of the experiments and prepared the manuscript: conceived of the study, participated in its design and coordination, collected and analyzed data, and prepared the manuscript. BJK carried out the animal studies, participated in oxidative relating enzyme assay. HJK carried out HMVEC cell assays. JMJ carried out N-glycan sequence analysis. HJY reared and supplied of versatile insects. JSH participated in the enzymatic function. BML edited related references. All authors read and approved the final manuscript.

\section{Funding}

Financial support was obtained from Rural Development Administration Basic Research project (PJ011853). The funding body allowed to the design of the study and collection, analysis, and interpretation of data and in writing the manuscript.

Availability of data and materials

All data generated or analyzed during this study are indicated in this article (with no patient data). The datasets generated during and /or analyzed during the current study are available from the corresponding author on reasonable request.

Ethics approval and consent to participate Studies involving animals were approved by the Laboratory Animals' Ethical Committee of the National Institute of Agricultural Sciences, RDA, South Korea (NIAS201605).

Consent for publication

Not applicable (not contain any individual person's data). 


\section{Competing interests}

The authors declare that they have no competing interests.

\section{Author details}

'Department of Agricultural Biology, National Institute of Agricultural Sciences, RDA, 166 Nongsaengmyung-Ro, Iseo-Myun, Wanju-Gun 55365, South Korea. ${ }^{2}$ Korean Basic Science Institute, Ochang 863-883, South Korea. ${ }^{3}$ Division of Toxicology, College of Pharmacy, Sungkyunkwan University, Chunchun-dong 300, Changan-ku, Gyeonggi-do, Suwon 440-746, South Korea.

Received: 8 April 2019 Accepted: 16 July 2020

Published online: 22 July 2020

\section{References}

1. Ahn MY, Lee YW, Ryu KS, Lee HS, Kim I, Kim JW. Effect of water and methanol extracts of cricket (Gyryllus bimaculatus) on alcohol metabolism. Korean J Pharmacogn. 2004;35(2):175-8.

2. Ahn MY, Kim MJ, Kwon RH, Hwang JS, Park KK. Gene expression profiling and inhibition of adipose tissue accumulation of $\mathrm{G}$. bimaculatus extract in rats on high fat diet. Lipid Health Dis. 2015;14:116.

3. Stull VJ, Finer E, Bergmans RS, Febvre HP, Longhurst C, Manter DK, Patz JA, Weir TL. Impact of edible cricket consumption on gut microbiota in healthy adults, a double-blind randomized crossover trial. Scientic Rep. 2018;8(1): 10762.

4. Robson R, Kundur AR, Singh I. Oxidative stress biomarkers in type 2 diabetes mellitus for assessment of cardiovascular disease risk. Diabetes Metab Syndr. 2018;12(3):455-62.

5. Zielińska E, Baraniak B, Karaś M. Antioxidant and anti-inflammatory activities of hydrolysates and peptide fractions obtained by enzymatic hydrolysis of selected heat-treated edible insects. Nutrients. 2017;9(9):970. https://doi.org/ 10.3390/nu9090970.

6. Uchimido R, Schmidt EP, Shapiro NI. The glycocalyx: a novel diagnostic and therapeutic target in sepsis. Crit Care. 2019;23(1):16.

7. Yang L, Wu S, Cooper JC, Paul MK, Cummings AL, Eletr ZM, Ben-Arye SL, Padler-Karavani V, Samli KN, Woods RJ. High-specificity affinity reagents for the detection of glycan sialylation. FASEB J. 2018;32(1 supplement):544.16 https://www.fasebj.org/doi/10.1096/fasebj.2018.32.1_supplement.544.16.

8. Banerjee DK, Zhang Z, Baksi K, Serrano-Negrón JE. Dolichol phosphate mannose synthase: a glycosyltransferase with unity in molecular diversities Glyconj J. 2017;34(4):467-79.

9. Ahn MY, Han JW, Hwang JS, Yun EY, Lee BM. Anti-inflammatory effect of glycosaminoglycan derived from Gryllus bimaculatus (a type of cricket, insect) on adjuvant-treated chronic arthritis rat model. J Toxicol Environ Health A. 2014;77(22-24):1332-45.

10. Ahn MY, Kim BJ, Kim HJ, Yoon HJ, Jee SD, Hwang JS, Park KK. Anti-obesity effect of Bombus ignitus queen glycosaminoglycans in rats on a high-fat diet. Int J Mol Sci. 2017;18:E681. https://doi.org/10.3390/ijms18030681.

11. Ahn MY, Hwang JS, Kim MJ, Park KK. Antilipidemic effects and gene expression profiling of the glycosaminoglycans from cricket in rats on a high fat diet. Arch Pharm Res. 2016;39(7):926-36.

12. Ahn MY, Kim BJ, Yoon HJ, Hwang JS, Park KK. Anti-diabetic effects of dung beetle glycosaminoglycan on $\mathrm{db}$ mice and gene expression profiling. Toxicol Res. 2018;34(2):151-62.

13. Schramm W, Tuna K, Chacko K, Sanchez V, Ahmed H, Liu L, Alli A. Characterization of urinary exosomes from diabetic hypertensive $\mathrm{db} / \mathrm{db}$ mice. FASEB J. 2018;32(1 supplement):624.35 https://www.fasebj.org/doi/1 0.1096/fasebj.2018.32.1_supplement.624.35.

14. Matsuzawa T, Yoshikawa T, Lida T, Kárpáti A, Kitano H, Harada R, Nakamura T, Sugawara A, Yamaguchi Y, Yanai K. Heparan sulfate in pancreatic cells contributes to normal glucose homeostasis by regulating insulin secretion. Biochem Biophys Res Comm. 2018;499(3):688-95.

15. Ziolkowski AF, Popp SK, Freeman C, Parish CR, Simeonovic CJ. Heparan sulfate and heparanase play key roles in mouse cell survival and autoimmune diabetes. J Clin Invest. 2012;122(1):132-41.

16. Ahn MY, Kim BJ, Kim HJ, Hwang JS, Jung YS, Park KK. Anti-aging effect and gene expression profiling of dung beetle glycosaminoglycan in aged rats. Biomater Res. 2017;21:5. https://doi.org/10.1186/s40824-017-0091-9.

17. Kim YS, Jo YY, Chang IM, Toida T, Park Y, Linhardt RJ. A new glycosaminoglycan from the giant african snail Achatina fulica. J Biol Chem. 1996;271(20):11750-5.
18. Ahn MY, Kim BJ, Kim HJ, Jin JM, Yoon HJ, Hwang JS, Park KK. Anticancer effect of dung beetle glycosaminoglycans on melanoma. BMC Cancer. 2019;19:9.

19. Bae EJ, Cho MJ, Kim SG. Metformin prevents an adaptive increase in GSH and induces apoptosis under the conditions of GSH deficiency in H4IIE cells. J Toxicol Environ Health A. 2007;70(15-16):1371-80.

20. Fratz EJ, Hunter GA, Ferreira C. Expression of murine 5-aminolevulinate synthase variants causes protoporphyrin IX accumulation and light-induced mammalian cell death. PLoS One. 2014;9(4):e93078.

21. Hansen BH, Hallmann A, Altin D, Jenssen BM, Ciesielski TM. Acute hydrogen peroxide $\left(\mathrm{H}_{2} \mathrm{O}_{2}\right)$ exposure does not cause oxidative stress in late-copepodite stage of Calanus finmarchicus. J Toxicol Environ Health A. 2017;80(16-18):820-9.

22. Shao G, Zhang S, Nie J, Li J, Tong J. Effects of melatonin on mechanisms involved in hypertension using human umbilical vein endothelial cells. J Toxicol Environ Health A. 2017;80(23-24):1342-8.

23. Herseth II, Volden V, Bolling AK. Particulate matter-mediated release of long pentraxin3 (PTX3) and vascular endothelial growth factor (VEGF) in vitro: limited importance of endotoxin and organic content. J Toxicol Environ Health A. 2017:80(2):105-19.

24. Yuan C, Liu P, Han X, Cui Q. Hypoglycemic effects of glycosaminoglycan from Urechis unicinctus in diabetic mice. J Med Food. 2015;18(2):190-4.

25. Ahn MY, Jung YS, Jee SD, Han JW, Hwang JS, Yun EY, Lee BM. Bloodpressure-lowering effect of glycosaminoglycan derived from Isaria sinclairii in spontaneously hypertensive rats. J Toxicol Environ Health A. 2013;76(6):391-9.

26. Lopes-Costa E, Abreu M, Gargiulo D, Rocha E, Ramos AA. Anticancer effects of seaweed compounds fucoxanthin and phloroglucinol, alone and in combination with 5-fluorouracil in colon cells. J Toxicol Environ Health A. 2017;80(13-15):776-87.

27. Krasiński R, Tchórzewski H, Lewkowicz P. Antioxidant effect of hyaluronan on polymorphonuclear leukocyte-derived reactive oxygen species is dependent on its molecular weight and concentration and mainly involves the extracellular space. Postepy Hig MedDosw. 2009;63:205-12.

28. Nunes KZ, Fioresi M, Marques VB, Vassallo DV. Acute copper overload induces vascular dysfunction in aortic rings due to endothelial oxidative stress and increased nitric oxide production. J Toxicol Environ Health A. 2018;81(8):218-28

29. Campo GM, Avenoso A, D'Ascola A, Campo S, Ferlazzo AM, Sama D, Calatroni A. Purified human plasma glycosaminoglycans limit oxidative injury induced by iron plus ascorbate in skin fibroblast cultures. Toxicol in Vitro. 2005;19(5):561-72.

30. Filippon L, Vanzin CS, Biancini GB, Pereira IN, Manfredini V, Sitta A, Peralba Mdo C, Schwartz IV, Giugliani R, Vargas CR. Oxidative stress in patients with mucopolysaccharidosis type II before and during enzyme replacement therapy. Mol Genet Metab. 2011;103(2):121-7.

31. Xie N, Huan M, Tian F, Gu Z, Li X. Low molecular weight heparin nebulization attenuates acute lung injury. Biomed Res Int. 2017;2017: 3169179.

\section{Publisher's Note}

Springer Nature remains neutral with regard to jurisdictional claims in published maps and institutional affiliations.

\section{Ready to submit your research? Choose BMC and benefit from}

- fast, convenient online submission

- thorough peer review by experienced researchers in your field

- rapid publication on acceptance

- support for research data, including large and complex data types

- gold Open Access which fosters wider collaboration and increased citations

- maximum visibility for your research: over $100 \mathrm{M}$ website views per year

At BMC, research is always in progress.

Learn more biomedcentral.com/submissions 